\title{
BMJ Open Quality Quality management systems in Aboriginal Community Controlled Health Services: a review of the literature
}

\section{Jenifer Olive Darr (D) , ${ }^{1}$ Richard C Franklin (D) , ${ }^{1}$ Kristin Emma McBain-Rigg (D) , Sarah Larkins, ${ }^{2}$ Yvette Roe, ${ }^{3}$ Kathryn Panaretto, ${ }^{4}$ Vicki Saunders, ${ }^{5}$ Melissa Crowe ${ }^{2}$}

To cite: Darr J0, Franklin RC, McBain-Rigg KE, et al. Quality management systems in Aboriginal Community Controlled Health Services: a review of the literature. BMJ Open Quality 2021;10:e001091. doi:10.1136/ bmjoq-2020-001091

- Additional supplemental material is published online only. To view, please visit the journal online (http://dx.doi.org/10. 1136/bmjoq-2020-001091).

Received 6 July 2020 Accepted 20 June 2021

\section{Check for updates}

(C) Author(s) (or their employer(s)) 2021. Re-use permitted under CC BY-NC. No commercial re-use. See rights and permissions. Published by BMJ.

${ }^{1}$ College of Public Health, Medical and Veterinary Sciences, James Cook University, Townsville, Queensland, Australia ${ }^{2}$ College of Medicine and Dentistry, James Cook University, Townsville, Queensland, Australia ${ }^{3}$ Molly Wardaguga Research Centre, Charles Darwin University, Brisbane,

Queensland, Australia

${ }^{4}$ Faculty of Medicine, The University of Queensland, Saint Lucia, Queensland, Australia

${ }^{5}$ First Peoples Health Unit,

Griffith University Faculty of Health, Gold Coast, Queensland, Australia

Correspondence to Jenifer Olive Darr; jenny.darr@my.jcu.edu.au

\section{ABSTRACT}

Background A national accreditation policy for the Australian primary healthcare (PHC) system was initiated in 2008. While certification standards are mandatory, little is known about their effects on the efficiency and sustainability of organisations, particularly in the Aboriginal Community Controlled Health Service (ACCHS) sector. Aim The literature review aims to answer the following: to what extent does the implementation of the International Organisation for Standardization 9001:2008 quality management system (QMS) facilitate efficiency and sustainability in the ACCHS sector?

Methods Thematic analysis of peer-reviewed and grey literature was undertaken from Australia and New Zealand PHC sector with a focus on First Nations people. The databases searched included Medline, Scopus and three Informit sites (AHB-ATSIS, AEI-ATSIS and AGIS-ATSIS). The initial search strategy included quality improvement, continuous quality improvement, efficiency and sustainability.

Results Sixteen included studies were assessed for quality using the McMaster criteria. The studies were ranked against the criteria of credibility, transferability, dependability and confirmability. Three central themes emerged: accreditation $(n=4)$, quality improvement $(n=9)$ and systems strengthening $(n=3)$. The accreditation theme included effects on health service expenditure and clinical outcomes, consistency and validity of accreditation standards and linkages to clinical governance frameworks. The quality improvement theme included audit effectiveness and value for specific population health. The theme of systems strengthening included prerequisite systems and embedded clinical governance measures for innovative models of care.

Conclusion The ACCHS sector warrants reliable evidence to understand the value of QMSs and enhancement tools, particularly given ACCHS (client-centric) services and their specialist status. Limited evidence exists for the value of standards on health system sustainability and efficiency in Australia. Despite a mandatory second certification standard, no studies reported on sustainability and efficiency of a QMS in PHC.

\section{INTRODUCTION}

Aboriginal Community Controlled Health Service (ACCHS) sector operates in dynamic and innovative settings. These settings are rich, intuitive environments remaining relevant and effective since the first ACCHS opened in Redfern in 1972. The sector has evolved to deliver comprehensive primary healthcare (PHC) to First Nations people. ${ }^{1}$ Nationally, the ACCHS sector includes more than 154 health organisations, specialising in a variety of health areas including population, environmental, tropical and public health. ${ }^{2}$ ACCHSs can be considered as boutique marketplaces for specialty training. ${ }^{3}$ ACCHSs deliver services that are groundbreaking, sustainable and effective in financially suppressed operating environments. ${ }^{4}$ These are traits demonstrating the continued relevance of the sector's resilience and strength-based approach, a true testament and acknowledgement to the culture and tenacity of the ACCHS sector nationally.

Australia spends $\$ 154.6$ billion on healthcare annually ${ }^{5}$ and performs well by international health service standards. ${ }^{6}$ Three tiers of healthcare delivery comprise the Australian healthcare system. Tertiary care (hospital specialist), secondary care (private specialists) and primary care (general practitioner (GP) and client). In some areas of service delivery, Australia performs well below international standards for equitable levels of healthcare coverage and outcomes. ${ }^{7}$ Most notably is the inequity among First Nations people, for whom chronic disease, psychosocial illness and the social determinants of health account for the majority of disparities in health outcomes between them and the rest of the Australian population. ${ }^{8}$

To quantify the quality and safety of the Australian health system, a significant commissioned study in 1994 reviewed adverse events experienced in tertiary hospitals in New South Wales and South Australia. ${ }^{9}$ The Quality in Australian Health Care Study identified the 
quality of healthcare in Australia as problematic ${ }^{10}: 16.6 \%$ of hospital admissions in South Australia and New South Wales resulted in adverse events (including client disability and longer hospital stay), and of the adverse events, $51 \%$ were deemed preventable. ${ }^{9}$ This evidence resulted in the establishment of the Quality in Australian Health Care taskforce $^{9}$ and subsequently a national expert advisory group and the Australian Council for Safety and Quality in Healthcare. ${ }^{11}{ }^{12}$ Part of the statutory authority's mission is to improve healthcare across the country. ${ }^{11}$

\section{STANDARDS AND QUALITY ASSESSIMENTS IN PHC}

Internationally, by the mid-2000s, there was a growing body of evidence concerning the importance of a systems approach to enhancing the quality of care in PHC. ${ }^{13-15} \mathrm{In}$ 2008, the Australian Commonwealth government introduced vital policy reforms to the Australian healthcare system, including a national accreditation framework. ${ }^{16}$ The Australian Commonwealth government holds primary responsibility for financing the primary care sector. ${ }^{16}{ }^{17}$ For many primary care providers, the national accreditation framework triggered the application of dual standards: the Royal Australian College of General Practitioners (RACGP) ${ }^{18}$ Standards and the International Organisation for Standardization (ISO) 9001:2008, quality management system (QMS), an international, whole-oforganisation certification. ${ }^{19}$ The RACGP non-legislated accreditation standard focuses on clinical service delivery and clinical governance arrangements with a choice of two national accreditation bodies of Australian General Practice Accreditation Limited (AGPAL) and General Practice Accreditation Plus. ${ }^{13}$

There are differences between accreditation and certification. The RACGP defines accreditation as peer-reviewed recognition of a health practice meeting requirements of Australian general practice standards, known as practice accreditation. ${ }^{18}$ Conversely, certification is a process whereby an authorised independent agency recognises individuals or healthcare organisations as meeting predetermined requirements, beyond those set by licensure. ${ }^{20}$ The other notable difference between accreditation and certification is the mandatory audit schedule as an inbuilt system of self-monitoring activities for the certification process. Audits routinely identify gaps for improvement and are integral components of clinical governance. Phillips describes clinical governance as a framework of strategies including clinical audits, clinical competence, client-directed interventions, risk management, education and training schedules and use of service information. Integration and a systematic approach to these strategies ensure services deliver quality and accountable healthcare. ${ }^{21}$ Illustrations of quality assessment models currently operating in Australia in the primary care context are presented in table 1 . The ACCHS sector applies two or more standards to their business operations and service delivery. ${ }^{19}$

In January 2013, the National Safety and Quality Health Standards (NSQHS) were introduced for all healthrelated facilities in Australia. ${ }^{22}$ The Queensland ACCHSs in 2010-2012, in compliance with the legislated national accreditation scheme, applied ISO 9001:2008 QMS together with the non-legislated RACGP Standard. ${ }^{18}$

\section{LITERATURE REVIEW QUESTION}

Ultimately, standards aim to improve outcomes; thus, the underlying logic of applying a QMS is (a) improving business performance and creating systems that are process dependent, (b) improving systems and microsystems via increased process dependency, (c) improved and interlinked microsystems providing enhanced service and (d) enhanced service sustainability and efficiency. ${ }^{13-15} 19$ 23-25 This literature review aims to answer the following: to what extent does the implementation of the ISO 9001:2008 QMS facilitate efficiency and sustainability in the ACCHS sector?

Table 1 Australian primary healthcare quality assessment models

\begin{tabular}{|c|c|c|c|c|}
\hline QA type & Aim & Rationale & Method & Outcome \\
\hline Practice accreditation & $\begin{array}{l}\text { Assess organisation } \\
\text { and delivery of specific } \\
\text { practice services }\end{array}$ & $\begin{array}{l}\text { Practices need to } \\
\text { demonstrate public } \\
\text { accountability }\end{array}$ & $\begin{array}{l}\text { Peer assessment } \\
\text { against explicit } \\
\text { standards }\end{array}$ & $\begin{array}{l}\text { Accreditation of practice } \\
\text { and development of } \\
\text { systems necessary for } \\
\text { quality improvement for } \\
\text { medical care of clients }\end{array}$ \\
\hline $\begin{array}{l}\text { International } \\
\text { Organisation for } \\
\text { Standardization (ISO) } \\
\text { model }\end{array}$ & $\begin{array}{l}\text { Implement international } \\
\text { norms for quality } \\
\text { systems }\end{array}$ & $\begin{array}{l}\text { Quality systems and } \\
\text { management processes } \\
\text { can be strengthened and } \\
\text { standardised to achieve } \\
\text { efficiencies }\end{array}$ & $\begin{array}{l}\text { Audit by ISO experts, } \\
\text { (not peers) against } \\
\text { generic international } \\
\text { standards }\end{array}$ & $\begin{array}{l}\text { Certificate of compliance } \\
\text { with standards for } \\
\text { whole-of-organisation } \\
\text { development }\end{array}$ \\
\hline
\end{tabular}

Adapted from Buetow and Wellingham, ${ }^{20} 2003$ p. 2. 


\section{METHODS}

Systematic, iterative searches of five databases (discussed below) occurred from October 2016 to October 2018. Key studies were identified and reviewed for quality, study characteristics, data collection and analyses, overall rigour, conclusions and implications.

\section{DATA SOURCES AND STUDY SELECTION}

Searches were performed in Medline, Scopus and three Informit databases (AHB-ATSIS, AEI-ATSIS and AGISATSIS). The literature searches were performed and conducted for the years 1995-2018. Exclusion criteria applied to studies are (i) not related to the Australian and New Zealand First Nations' PHC context and (ii) not in English. Grey literature searches were picked up from reference lists of identified literature. Initial searches found limited studies using the search term 'quality management system'. Using the broader terms 'continuous quality improvement', 'quality improvement' and 'systems approach' identified 251 studies from a title and abstract review. In a second iterative phase, the terms 'accreditation' and 'systems strengthening' were included to narrow down the search to the final sixteen studies. In total, 7675 studies were identified, and of these, 401 were reviewed (figure 1). The second phase identified 52 studies in full-text review with 16 studies selected for the final review. The initial search criteria were discussed with an academic librarian with search criteria adaptations and presented using the Preferred Reporting Items for Systematic Reviews and Meta-Analysesframework (figure 1). ${ }^{26}$

The eligibility criteria were as follows:

1. PHC with a focus on Aboriginal and Torres Strait Islander or First Nation populations.

2. Publications between 1 January 1995 and October 2018.

3. Publications in English.

4. Human.

5. Studies in the Australian and New Zealand PHC context.

6. Application of quality improvement (and variants) and its impact on efficiency and sustainability.

\section{LITERATURE QUALITY}

The McMaster framework was applied to explore indicators of quality in the sixteen included studies. ${ }^{27}$ A quality assessment of the studies was performed using the representative criteria of credibility, transferability, dependability and confirmability, which were established to separate the sixteen studies into four categories as listed below (results displayed in table 2) to quantify the quality.

Category one includes studies of high quality with all the representative criteria confirmed;

Category two represents studies with limited transferability;

Category three has not confirmed means of dependability and confirmability.
Category four studies have only one of the four representative criteria, confirmed from the synthesis of the study.

\section{RESULTS}

A total of sixteen studies met the eligibility criteria (as evidenced in figure 1); of these, fifteen were from Australia, with one from a New Zealand general practice context. Of the sixteen studies, three were systematic reviews, and nine were observational studies. Ten studies were participatory action research in design with the introduction of two conceptual models as improvement models for trial in primary care. Two studies were audits (desktop and chart). The desktop review of published literature was on health systems and structures throughout each state and territory in the Australian healthcare system. The inclusion of the systematic reviews was due to the limited literature on a QMS. These reviews explain the systematic nature to QMSs.

Table 3 shows how the 16 included articles were categorised by practice setting/context, the article's overarching theme and details on the type of study.

Iterative thematic analysis of the literature selected for review highlighted three themes that are also reflected in the broader PHC sector as shown in online supplemental table 4. Theme 1: systems strengthening $(n=3)$ includes subcategories of systems thinking and system reform. Theme 2: quality improvement $(n=9)$ includes eight observational studies with subcategories of audits and continuous quality improvement. Theme 3: accreditation $(n=4)$ includes two studies discussing the application of standards employed in Australian primary care and the validity of these across healthcare contexts, and a further two studies focused on RACGP practice accreditation. One is a pilot study of RACGP Standards applied in a New Zealand GP context, from GPs' perspectives. Another study focuses on the AGPAL surveyor perspective, of the impact of RACGP accreditation, on patient safety in Australian general practice environments.

\section{THEME 1: SYSTEMS STRENGTHENING}

A key theme from three publications is systems strengthening. The WHO defines this as '(i) a process identifying and implementing policy changes and practice in a country's health system to be responsive to its health and health system challenges; (ii) any array of initiatives and strategies improving health systems functions, leading to better access, coverage, quality or efficiency'. ${ }^{28}$

Systems strengthening refers to the supporting instruments that enhance the effective delivery of health services such as continuous improvement, audits, staffing models, staff performance and review frameworks and communication pathways to promote systems thinking. ${ }^{29}$ Bailie's 'Partnership Learning Model' (PLM) ${ }^{30}$ uses integrated concepts for the translation of knowledge to enhance health outcomes. The PLM is not dissimilar to 

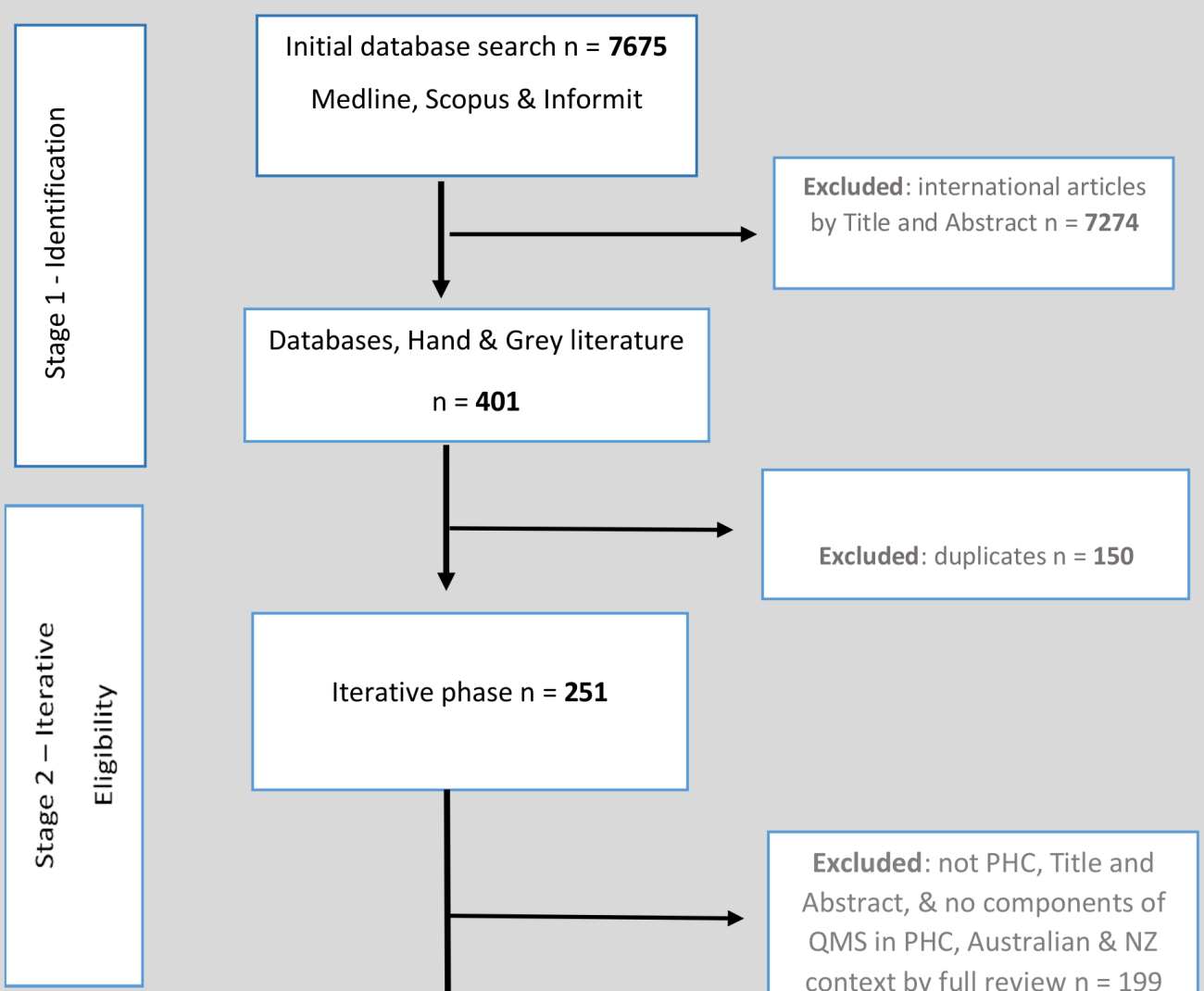

Iterative phase $\mathrm{n}=\mathbf{2 5 1}$

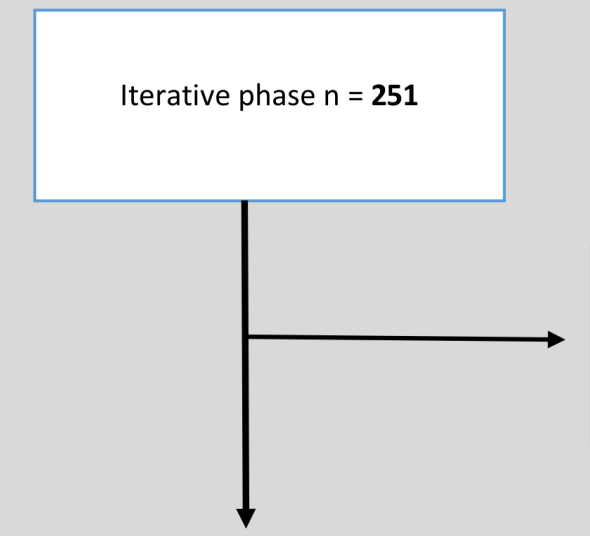

Excluded: not PHC, Title and

Abstract, \& no components of

QMS in PHC, Australian \& NZ

context by full review $n=199$
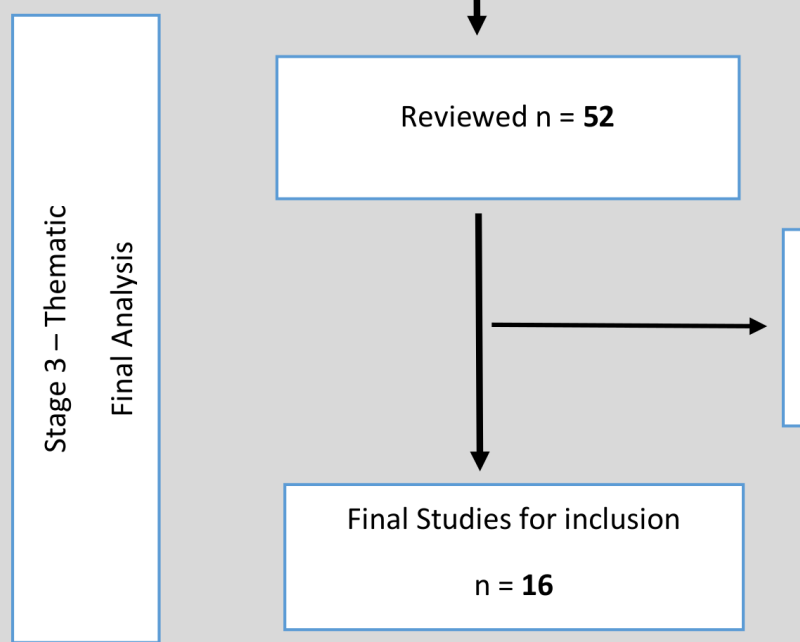

Excluded: no variants of QMS in

PHC setting \& Efficiency and

Sustainability in Australian \& NZ

context $\mathrm{n}=36$

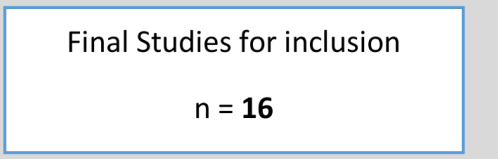

Exclusion criteria - international studies not

related to Australian \& New Zealand First

Nations' PHC Context. Non English.

Key words -S1 accreditation* OR "Continuous Quality Improvement" OR "quality improvement" OR certification* OR ISO9001 OR "Continuous Quality Improvements" OR "quality improvements" AND S2 "Aboriginal Health Service" OR "Aboriginal Health Services" OR "Indigenous Health Service" OR "Indigenous Health Services" AND S3 "Healthcare efficiency" OR "Health care efficiency" OR "Healthcare efficiencies" OR "Health care efficiencies"

Figure 1 Preferred Reporting Items for Systematic Reviews and Meta-Analyses diagram literature review. ISO, International Organisation for Standardization; NZ, New Zealand; PHC, primary healthcare; QMS, quality management system.

the current working business model used by ACCHSs. This ACCHS business model has evolved since ACCHS sector inception in 1972 and now aligns to a holistic ACCHS philosophy and responsive culture. ${ }^{31}$ Panaretto reports that in recent times ACCHSs have been building their capacity to use, collect and compile regional service data to monitor the health status of client cohorts, ${ }^{32}$ a process not dissimilar to the PLM concept described by Bailie. $^{30}$

Dwyer argued that the health systems reforms implemented by each state and territory, towards centralisation, would be counterproductive to stemming the 
Table 2 Study quality assessed using the McMaster framework

\begin{tabular}{|c|c|c|c|c|c|c|}
\hline Theme & Studies & Credibility & Transferability & Dependability & Confirmability & Category \\
\hline QI & 1. Bailie et $\left.a\right|^{37}$ & $\bullet$ & & & & 4 \\
\hline QI & 2. Bailie et $a /^{36}$ & $\bullet$ & & - & $\bullet$ & 2 \\
\hline Q। & 3. Bailie et $a /^{34}$ & $\bullet$ & & $\bullet$ & - & 2 \\
\hline SS & 4. Bailie et $\left.a\right|^{30}$ & $\bullet$ & $\bullet$ & & & 3 \\
\hline$A C$ & 5. Braithwaite et $a l^{23}$ & - & - & $\bullet$ & - & 1 \\
\hline$A C$ & 6. Braithwaite et al ${ }^{15}$ & $\bullet$ & $\bullet$ & $\bullet$ & $\bullet$ & 1 \\
\hline QI & 7. Brennan et $a l^{40}$ & $\bullet$ & $\bullet$ & $\bullet$ & $\bullet$ & 1 \\
\hline$A C$ & 8. Buetow 20 & $\bullet$ & $\bullet$ & & & 3 \\
\hline SS & 9. Dwyer ${ }^{33}$ & $\bullet$ & & $\bullet$ & $\bullet$ & 2 \\
\hline$A C$ & 10. Elnour et $a l^{41}$ & & & & - & 4 \\
\hline QI & 11. Gardner et a/ ${ }^{35}$ & $\bullet$ & & $\bullet$ & $\bullet$ & 2 \\
\hline QI & 12. Marley et $a l^{24}$ & $\bullet$ & $\bullet$ & $\bullet$ & $\bullet$ & 1 \\
\hline Q। & 13. McDonald ${ }^{38}$ & & & $\bullet$ & & 4 \\
\hline SS & 14. Phillips et $\left.a\right|^{21}$ & $\bullet$ & $\bullet$ & $\bullet$ & $\bullet$ & 1 \\
\hline QI & 15. Ralph et $\left.a\right|^{25}$ & $\bullet$ & $\bullet$ & $\bullet$ & $\bullet$ & 1 \\
\hline QI & 16. Schierhout et $a^{39}$ & $\bullet$ & & • & $\bullet$ & 2 \\
\hline
\end{tabular}

AC, accreditation; QI, quality improvement; SS, systems strengthening.

burgeoning tide of chronic disease plaguing the primary and secondary care levels of the Australian health system. ${ }^{33}$ Dwyer flagged a need for better, innovative models of care. ${ }^{33}$ The clinical governance models examined by Phillips describe clinical governance as a systematic, integrated approach to assuring safe, good, quality healthcare.$^{21}$ Phillips' endorsement of the ACCHS model as a systems approach at an organisational level may lead to effective PHC, a decrease in chronic disease and an efficient business model. ${ }^{21}$ Phillips describes the ACCHS sector as leaders in clinical governance in Australia with valuable lessons for primary care more broadly. The knowledge gap in PHC, Phillips reported, was the fragmented evidence for the outcomes of clinical governance, with few models addressing safety, efficiency, sustainability and the cost for primary care. ${ }^{21}$

There is a need to understand what quality systems are being used in the ACCHS sector (and how) to (i) drive and holistically measure the quality of care delivered by clinical teams and (ii) measure the quality of the organisation through corporate governance.

\section{THEME 2: QUALITY IMPROVEMENT}

Quality improvement is one of the six building blocks defined by the WHO for health systems strengthening. ${ }^{30}$ Audits augment an organisation's' risk management and clinical governance system. ${ }^{28}$ Seven observational studies authored by one research group describe the benefits and improvements of independent audit tools across a variety of health programmes conducted within Aboriginal primary care settings. ${ }^{25} 34-39$

The common feature in these nine studies reaffirms that audits, when designed with specific indicators and under the right conditions, have the propensity to enhance and improve health service programmes. ${ }^{24} 2540$ From a systems perspective, the application of independent quality tools operates external to an organisation's compliance standard. Increasingly, health services implement (at a minimum) dual standards of quality enhancement systems. The result is a duplication of multiple audit processes through multiple quality enhancement tools, coupled with the uptake of independent audit data, into multiple legislated standard frameworks. The harmonisation of these quality tools for the ACCHS business raises questions of efficiency and sustainability. Under these conditions, the onus rests on the organisation to systematise the different standard processes into a QMS for national compliance. The responsibility to reduce duplication, optimise financial outlays, maximise human resource efficiencies and successfully operate health service delivery in a fiscally constrained environment is burdensome for ACCHS leadership. ${ }^{19}$

Based on the evidence presented by these studies, gaps in knowledge remain: What added value are stand-alone audits offering to the existing QMS certification operating within the organisation? How efficient and sustainable are these stand-alone quality systems? Based on the synthesis and the questions raised, the overarching question being posed is as follows: Have these quality systems driven efficiency in the ACCHS sector?

All authors in themes 1 and 2 recognised vertical programme funding between state and federal government and the effectiveness of government policy as the common limitations and disablers to harmonisation supported by Phillips ${ }^{21}$ and Dwyer. ${ }^{33}$ 
Table 3 Article analysis by category

\begin{tabular}{llll}
\hline Author and year & Context & Theme & Type of study \\
\hline Dwyer, ${ }^{33} 2004$ & $\begin{array}{l}\text { Australian healthcare } \\
\text { system }\end{array}$ & Health systems strengthening & $\begin{array}{l}\text { DESKTOP AUDIT } \\
\text { Australian states and territories }\end{array}$ \\
Phillips et $a{ }^{21}{ }^{21} 2010$ & $\begin{array}{l}\text { Australian general } \\
\text { practice (GP) primary care }\end{array}$ & $\begin{array}{l}\text { Health Systems strengthening } \\
(\mathrm{n}=25 \text { databases and 19 high- } \\
\text { quality studies) }\end{array}$ & $\begin{array}{l}\text { Systems strengthening } \\
\text { SYSTEMATIC REVIEW }\end{array}$
\end{tabular}

\begin{tabular}{|c|c|c|}
\hline Bailie et $a l,{ }^{30} 2013$ & $\begin{array}{l}\text { Primary care } \\
\text { Aboriginal health services }\end{array}$ & $\begin{array}{l}\text { Health systems strengthening } \\
\text { ( } n=\text { various concepts) }\end{array}$ \\
\hline Bailie et al, ${ }^{36} 2008$ & $\begin{array}{l}\text { Primary care } \\
\text { Aboriginal health services }\end{array}$ & $\begin{array}{l}\text { Quality improvement } \\
\text { ( } n=40-50 \text { health centres across } \\
\text { four Australian states/territories) }\end{array}$ \\
\hline Bailie et al, ${ }^{34} 2010$ & $\begin{array}{l}\text { Primary care } \\
\text { Aboriginal health services }\end{array}$ & $\begin{array}{l}\text { Quality improvement } \\
\text { ( } \mathrm{n}=\text { study protocols across six } \\
\text { states/territories over } 5 \text { years) }\end{array}$ \\
\hline Bailie et al, ${ }^{37} 2007$ & $\begin{array}{l}\text { Primary care } \\
\text { Aboriginal health services }\end{array}$ & $\begin{array}{l}\text { Quality improvement } \\
\text { ( } \mathrm{n}=12 \text { community health centres) }\end{array}$ \\
\hline
\end{tabular}

Promotion of systems strengthening for organisational performance through the application of stratified modelling

OBSERVATIONAL STUDY

Participatory Action Research (PAR) design

Promotion of $A B C D E$ Project as audit tools for chronic disease management

OBSERVATIONAL STUDY

PAR design

Promotion of audit tools for indigenous health services OBSERVATIONAL STUDY

PAR design

Promotion of $A B C D$ tools in a CQI approach for service delivery; effective and sustainable health programmes

OBSERVATIONAL STUDY

PAR design

\begin{tabular}{|c|c|c|c|}
\hline Brennan et al, ${ }^{40} 2012$ & Australian healthcare & $\begin{array}{l}\text { Quality improvement } \\
\text { ( } \mathrm{n}=41 \text { instruments) }\end{array}$ & $\begin{array}{l}\text { Instruments for CQI/team success factors } \\
\text { SYSTEMATIC REVIEW }\end{array}$ \\
\hline Gardner et $a l,{ }^{35} 2010$ & $\begin{array}{l}\text { ACCHS-Aboriginal } \\
\text { health service enrolment } \\
\text { in ABCD Project }\end{array}$ & $\begin{array}{l}\text { Quality improvement } \\
\text { ( } n=48 \text { participants) }\end{array}$ & $\begin{array}{l}\text { AUDIT TOOLS in Aboriginal health } \\
\text { OBSERVATIONAL STUDY } \\
\text { PAR design }\end{array}$ \\
\hline McDonald, ${ }^{38} 2013$ & $\begin{array}{l}\text { ACCHS-Aboriginal } \\
\text { health service }\end{array}$ & $\begin{array}{l}\text { Quality improvement } \\
\text { ( } n=8 \text { participants) }\end{array}$ & $\begin{array}{l}\text { AUDIT TOOLS in INDIGENOUS HEALTH, healthy } \\
\text { community assessment tool and CQI } \\
\text { OBSERVATIONAL STUDY } \\
\text { PAR design }\end{array}$ \\
\hline Buetow, ${ }^{20} 2003$ & $\begin{array}{l}\text { Accreditation in GP in } \\
\text { New Zealand (NZ) and } \\
\text { Australia }\end{array}$ & Accreditation & $\begin{array}{l}\text { AUSTRALIAN and NZ GP ACCREDITATION } \\
\text { NON-SYSTEMATIC REVIEW }\end{array}$ \\
\hline Elnour et al, ${ }^{41} 2014$ & $\begin{array}{l}\text { Accreditation in GP, } \\
\text { Australian healthcare } \\
\text { system }\end{array}$ & $\begin{array}{l}\text { Accreditation } \\
\text { ( } \mathrm{n}=10 \text { participants })\end{array}$ & $\begin{array}{l}\text { GP ACCREDITATION and patient safety } \\
\text { OBSERVATIONAL STUDY }\end{array}$ \\
\hline $\begin{array}{l}\text { Braithwaite et al, } \\
2006\end{array}$ & $\begin{array}{l}\text { Tertiary care and primary } \\
\text { care }\end{array}$ & $\begin{array}{l}\text { Accreditation } \\
\text { ( } n=\text { multilevel, multidiscipline, } \\
\text { multimethod) }\end{array}$ & $\begin{array}{l}\text { Hospital and primary care ACCREDITATION } \\
\text { PAR design }\end{array}$ \\
\hline $\begin{array}{l}\text { Braithwaite et } a l,{ }^{15} \\
2011\end{array}$ & $\begin{array}{l}\text { Australian GP, aged care } \\
\text { and acute setting }\end{array}$ & $\begin{array}{l}\text { Accreditation } \\
\text { ( } \mathrm{n}=12 \text { interrelated studies) }\end{array}$ & $\begin{array}{l}\text { Twelve interrelated studies of accreditation } \\
\text { PAR design }\end{array}$ \\
\hline
\end{tabular}

ABCD, Audit for Best practice Chronic Disease clinical audit tool; ABCDE, The Audit and Best practice for Chronic Disease Expansion project clinical audit tool; ACCHS, Aboriginal Community Controlled Health Service; AHS, Aboriginal HealthService; CQI, Continuous Quality Improvement; NT, Northern Territory; T2D, Type 2 Diabetes.

\section{THEME 3: ACCREDITATION}

Four studies were included in the accreditation theme. Two studies related to the RACGP Standards (Buetow and Wellingham ${ }^{20}$ and Elnour $\left.{ }^{41}\right)$. The remaining two studies focused on the ACCREDIT Project by Braithwaite. ${ }^{15} 23$
Three of the four studies investigated the need for vendors and consumers, through research, to understand the value, impact and benefit of accreditation.

At a health service level, standards of compliance (such as RACGP accreditation (Australia) and QMS 
certification) provide a level of quality and safety for clients. Buetow and Wellingham discuss whether the non-legislated RACGP Standards provide consistency or validity, with a requisite for the RACGP Standard to be an inclusion to the clinical governance framework in the NZ context. ${ }^{20}$ Braithwaite's 2006 and 2011 studies, performed in the Australian context, evaluate the validity, impact and value of accreditation. ${ }^{1523}$ A knowledge gap highlighted by Braithwaite's research is the need for reliable evidence on the efficiency and effectiveness of accreditation in achieving organisational improvements and on the value of accreditation in cost-benefit terms. ${ }^{15} 23$ The task of applying dual accreditation standards is a large assignment, is resource intensive and is an expensive process for any organisation, its leadership and staff to undertake. The stand-alone quality enhancement tools such as audit tools and non-legislated standards operate external to the organisations' certification system. The conjecture is that these additional quality systems and non-legislated standards are extra cost imposts and compliance requirements, stretching existing resources and inhibiting a sustainable, systematic and efficient healthcare delivery. These discussions prompted the following questions: Is there value in the application of dual systems at the primary care level? How much do they cost? Are double accreditation/certification standards sustainable? How are these standards impacting the health and community outcomes of First Nations people?

Of the 16 studies, ten studies refer to efficiency, effectiveness and sustainability. Phillips and Braithwaite were the only authors to contextualise efficiency and sustainability to primary care. ${ }^{21} 23$ Braithwaite's 2006 study sought to measure these quality criteria through a prospective research study across 12 countries. ${ }^{23}$ Eight studies discussed efficiency, effectiveness and sustainability as outcome measures specific to the interventions being applied in these studies, but not in the context of a QMS as a standard used to the delivery of PHC services. The limitation evident in this review is an absence of studies exploring the application of a QMS certification standard in an Australian primary care context and its facilitation of efficiency and sustainability for health services.

\section{LITERATURE QUALITY}

Table 2 presents the study themes and literature quality based on the criteria of credibility, transferability, dependability and confirmability. Six studies in category one met all of the criteria for overall rigour. ${ }^{27}$ Five studies were graded as category two, two studies as category three and three studies as category four (table 2).

\section{DISCUSSION}

It is over a decade since the implementation of Australian health system standards, with limited evidence of the impact, sustainability and efficiency of these initiatives on health service delivery in the PHC sector. ${ }^{16}$ Nationally, the ACCHS sector has more than 154 health organisations that are specialists in their healthcare. They are considered boutique markets where holistic and rewarding training experiences in comprehensive PHC are sourced. ${ }^{3}$

Systematic searches of the literature found no studies currently addressing the efficiency and sustainability of implementing ISO 901:2008 standard/QMS and quality enhancement tools in the ACCHS sector. The standards and quality enhancement tools presently used do not appear to promote efficiency and sustainability within the ACCHS business model. Since 2010, a proliferation of accreditation standards has been introduced into the ACCHS sector (due to the highly specialised set of care services provided in an ACCHS) and a massive increase in the number of certification bodies. At least nine different standards operate in the ACCHS, maintaining a silo effect to certification and accreditation standards. The limited evidence suggests a duplication and lack of clarity on the appropriateness of the diversity of standards currently being used.

Additionally, anecdotal evidence indicates there are, on average, nine standards in operation for ACCHSs in Queensland and Victoria. ${ }^{42}$ These standards include the RACGP Standards (2015), ISO Certification QMS 9001:2015, NSQHS Standards and National Disability Insurance Scheme (NDIS) Practice Standards, Human Services Quality Framework (for services that deliver child safety and disability services in Queensland) and Victorian Human Service Standards. Current national aged care standards include the National Aboriginal and Torres Strait Islander Flexible Aged Care Standards, Accreditation Standards, Home Care Standards and Transition Care Standards. After 1 July 2019, all aged care standards need to meet the one in Aged Care Quality Standards. ${ }^{42}$

If the standards' design is to improve the quality of business and client outcomes, the proliferation of certification/accreditation standards for PHC services raises the following question: How can health services provide quality services while applying several standards with limited synergy? The application of dual standards increases staffing costs, is a financial burden and cost impost and removes the focus from providing quality services, with flow-on effects for client health and wellbeing, community prosperity and a systematic approach to quality outcomes. The health disparity that First Nations people continue to experience is a result of centuries of uninformed, myopic and reactive policy, a stance supported by Pearson and Hunter. ${ }^{43} 44$

The national accreditation policy was a catalyst for the emergence of a new workforce to support the application of standards across every level of the Australian healthcare system. At the regional level for the ACCHS sector, diverse new roles were established to support the application of multiple standards. New roles included quality coordinators, quality managers, auditors and an increase in certification bodies nationally. Their responsibility is for the application, assessment, monitoring and management of these standards. This research aims to contribute 
to the body of substantial evidence on the efficiency and sustainability of standards within the ACCHS sector.

The limited synergy of multiple standards is burdensome for ACCHSs in fiscally constrained environments. Furthermore, this burden reduces efforts to obtain sustained, holistic health and well-being outcomes for First Nations people. ${ }^{45}$ The missing component is the substantiated evidence that standards improve the efficiency and sustainability of ACCHS's business environment. The contemporary evidence supporting this statement is the number of standards any one ACCHS applies for compliance.

To comprehensively address health inequality at various levels requires an explicit focus on issues of participation, governance and the politics of power, decision making and empowerment. ${ }^{46}$ The review findings and the status of onerous compliance standards for ACCHSs prompt questions of the accountability of state and federal governments in monitoring the synergy of certification and accreditation industry standards. The legislation is yet to be examined and assessed on how efficient and sustainable a national accreditation framework is for the Australian PHC sector.

\section{STRENGTHS AND LIMITATIONS}

This study identified several independent quality enhancement tools in operation in the compliance and governance area for PHC services. The PHC sector at a minimum applies dual accreditation standards. The literature raised more questions to explore: the value of the application of multiple standards in individual health services and how sustainable these are in terms of their business model. This study does not include the assessment of value, as this is the focus of a subsequent search and review as part of the overarching research project. A limitation identified in the literature was the lack of evidence for efficiency and sustainability of stand-alone quality systems and stand-alone audit tools and their subsequent fit and synergy with applied certification standards by ACCHS. In this review, there was an absence of studies exploring the extent of a QMS in an Australian primary care context and its facilitation of efficiency and sustainability for health services. While search terms could be expanded to include concepts of efficiency and sustainability, this is the focus of further research questions in the field: What are the quality systems used in the ACCHS sector? How do these quality systems drive and holistically measure the quality of care delivered? How are these standards impacting the health and community outcomes of First Nations people? The strengths of the gaps in the literature and the questions posed set the course and dialogue for the next level of research activity.

\section{CONCLUSION}

The application of multiple mandated certification standards, plus independent quality enhancement tools, is the current accreditation status for ACCHSs, creating a level of limited synergy between each 'quality system'. There is little evidence assessing the efficiency and sustainability of multiple standards and quality enhancement tools on ACCHS business model efficiencies. There are unanswered questions as to whether the implementation of quality systems has driven efficiency and sustainability in the ACCHS sector. The benefit of multiple standards for PHC services, and their impact on the health and wellbeing outcomes of First Nations people (and their corresponding community benefit), has not been explored adequately to assert its value.

The review findings and the status of onerous compliance standards for ACCHSs prompt questions about the accountability of state and federal governments, to monitor the synergy of compliance standards in a systems approach to healthcare. It is crucial to ensure health services are not overburdened with compliance standards and extraneous operating expenses at the cost of delivering quality health services. The Australian government funds PHC services to provide substantial, high-quality health outcomes for First Nations people, for whom chronic disease, psychosocial illness and the social determinants of health account for the majority of disparities in health outcomes. As the burden of chronic illness grows, pressure mounts on primary care to be efficient in its service delivery. Research in ACCHSs for dependable evidence on the efficiency and sustainability of compliance standards and effectiveness of quality systems in achieving organisational improvements is vital.

Twitter Richard C Franklin @Franklin_R_C

Contributors The first author of this work was responsible for the search terms and results and the preparation of this manuscript. All subsequent authors checked over the search terms and search results and assisted in the development of the discussion and the final drafting of the manuscript.The members of the authorship team were responsible for their assistance in the development of the research design and editorial assistance in the design of this literature review.

Funding The authors have not declared a specific grant for this research from any funding agency in the public, commercial or not-for-profit sectors.

Competing interests None declared.

Patient consent for publication Not required.

Provenance and peer review Not commissioned; externally peer reviewed.

Data availability statement All data relevant to the study are included in the article or uploaded as supplementary information.

Author note Recognition-We pay honour to our First Nation ancestors and acknowledge the custodians of the country on whose land we live and work. Qualification-First Nations people is the first authors' designated title for Australian Aboriginal and Torres Strait Islander people.

Supplemental material This content has been supplied by the author(s). It has not been vetted by BMJ Publishing Group Limited (BMJ) and may not have been peer-reviewed. Any opinions or recommendations discussed are solely those of the author(s) and are not endorsed by BMJ. BMJ disclaims all liability and responsibility arising from any reliance placed on the content. Where the content includes any translated material, BMJ does not warrant the accuracy and reliability of the translations (including but not limited to local regulations, clinical guidelines, terminology, drug names and drug dosages), and is not responsible for any error and/or omissions arising from translation and adaptation or otherwise.

Open access This is an open access article distributed in accordance with the Creative Commons Attribution Non Commercial (CC BY-NC 4.0) license, which permits others to distribute, remix, adapt, build upon this work non-commercially, and license their derivative works on different terms, provided the original work is 
properly cited, appropriate credit is given, any changes made indicated, and the use is non-commercial. See: http://creativecommons.org/licenses/by-nc/4.0/.

ORCID iDs

Jenifer Olive Darr http://orcid.org/0000-0002-6638-863X

Richard C Franklin http://orcid.org/0000-0003-1864-4552

Kristin Emma McBain-Rigg http://orcid.org/0000-0001-6597-1359

\section{REFERENCES}

1 NACCHO. NACCHO history of Aboriginal health from 1967. Canberra: NACCHO, 2014: 1-29.

2 Alford K. Economic value of Aboriginal community controlled health services. Canberra: NACCHO, 2014: 1-21.

3 Larkin S. Race blindness in neo-liberal and managerial approaches to Indigenous administration. IJCIS 2009;2:36-42.

4 Alford K. Investing in Aboriginal Community Controlled Health Makes Economic Sense. In: Economic value of Aboriginal community controlled health services. Canberra: NACCHO, 2014: 1-21.

5 AlHW Australian Government. Health expenditure Australia 2013 - 2014: analysis by sector (Category number 55). Canberra: AlHW, 2015.

6 AlHW Australian Government. Health expenditure Australia 2014 15. In: Health and welfare expenditure. series no. 57 (cat No. HWE 67. Canberra: AlHW, 2016: 57.

7 Wenitong M, Mokak R, Councillor $\mathrm{H}$, et al. Rising to the health challenge for Aboriginal and Torres Strait Islander peoples: what will it take? Med J Aust 2007;186:491-2.

8 Gomersall JS, Gibson O, Dwyer J, et al. What Indigenous Australian clients value about primary health care: a systematic review of qualitative evidence. Aust N Z J Public Health 2017;41:1-7.

9 Wilson RM, Runciman WB, Gibberd RW, et al. The quality in Australian health care study. Med J Aust 1995;163:458-71.

10 Richardson JR. Priorities of health policy: cost shifting or population health. Aust New Zealand Health Policy 2005;2:1.

11 Rubin GL, Leeder SR. Health care safety: what needs to be done? Med J Aust 2005;183:529-31.

12 Smallwood RA. The safety and quality of health care: from Council to Commission. Med J Aust 2006;184:39-40.

13 Wise M, Angus S, Harris E. National appraisal of continuous quality improvement Inititiatives in Aboriginal and Torres Strait Islander primary health care. final report. Melbourne: The Lowitja Institute, 2013.

$14 \varnothing v r e t v e i t$ J. The quality of health purchasing. Int J Health Care Qual Assur Inc Leadersh Health Serv 2003;16:116-27.

15 Braithwaite J, Westbrook J, Johnston B, et al. Strengthening organizational performance through accreditation research-a framework for twelve interrelated studies: the ACCREDIT project study protocol. BMC Res Notes 2011;4:390

16 Bennett CC. Beyond the blame game: accountability and performance benchmarks for the next Australian health care agreements. Canberra, ACT: NHHR Commission, 2008: 189. 31-2.

17 Segal L. Health \& Hospital Reform Commission: Prevention Theme Opinion Piece A vision for pirmary care: Funding and other System Factors for optimising the primary care contribution to the communtiy's health. University of South Australia, 2008: 1-22.

18 RACGP. RACGP standards for general practice 4th edition. East Melbourne VIC: Royal Australian College of General Practitioners, 2010: 159.

19 Silburn K, Thorpe A, Carey L. Is Funder reporting undermining service delivery? compliance reporting requirements of Aboriginal community controlled health organisations in Victoria. The. Melbourne: Lowitja Institute, 2016: 1-40.

20 Buetow SA, Wellingham J. Accreditation of general practices: challenges and lessons. Qual Saf Health Care 2003;12:129-35.

21 Phillips CB, Pearce CM, Hall S, et al. Can clinical governance deliver quality improvement in Australian general practice and primary care? A systematic review of the evidence. Med J Aust 2010;193:602-7.

22 Australian Commission Safety and Quality in Healthcare. NSQHS standards in 2013: transforming the safety and quality of health care. Sydney NSW, 2001: Commonwealth of Australia 2014, 2014.
23 Braithwaite J, Westbrook J, Pawsey M, et al. A prospective, multi-method, multi-disciplinary, multi-level, collaborative, socialorganisational design for researching health sector accreditation [LP0560737]. BMC Health Serv Res 2006;6:1-10.

24 Marley JV, Nelson C, O'Donnell V, et al. Quality indicators of diabetes care: an example of remote-area Aboriginal primary health care over 10 years. Med J Aust 2012;197:404-8.

25 Ralph AP, Fittock M, Schultz R, et al. Improvement in rheumatic fever and rheumatic heart disease management and prevention using a health centre-based continuous quality improvement approach. BMC Health Serv Res 2013;13:1-13.

26 Moher D, Liberati A, Tetzlaff J. Preferred Reporting Items for Systematic Reviews and Meta-Analyses: The PRISMA Statement 2009 [cited 2015. PRISMA flowchart]. Available: http://www.prisma. statement.org

27 Letts L, Wilkins S, Law M. Critical Review Form - Qualitative Studies (Version 2.0). McMaster University: University of South Australia, 2007

28 World Health Organisation. World health organisation health systems strengthening glossary. Geneva: WHO, 2011: 1-22.

29 Wilkinson R, Marmot M, eds. Social Determinants of Health The Solid Fact. 2nd ed. Denmark: World Health Organisation Europe, 2003.

30 Bailie R, Matthews V, Brands J, et al. A systems-based partnership learning model for strengthening primary healthcare. Implementation Sci 2013;8:1-12.

$31 \mathrm{NACCHO}$. Investing in Aboriginal community controlled health makes economic sense. Canberra: NACCHO, 2014: 1-21.

32 Panaretto KS, Wenitong M, Button S, et al. Aboriginal community controlled health services: leading the way in primary care. Med J Aust 2014;200:649-52.

33 Dwyer JM. Australian health system restructuring - what problem is being solved? Aust New Zealand Health Policy 2004;1:6.

34 Bailie R, Si D, Shannon C, et al. Study protocol: National research partnership to improve primary health care performance and outcomes for Indigenous peoples. BMC Health Serv Res 2010;10:129.

35 Gardner KL, Dowden M, Togni S, et al. Understanding uptake of continuous quality improvement in Indigenous primary health care: lessons from a multi-site case study of the audit and best practice for chronic disease project. Implementation Sci 2010;5:1-14.

36 Bailie R, Si D, Connors C, et al. Study protocol: audit and best practice for chronic disease extension (ABCDE) project. BMC Health Serv Res 2008;8:184.

37 Bailie RS, Si D, O'Donoghue L, et al. Indigenous health: effective and sustainable health services through continuous quality improvement. Med J Aust 2007;186:525-7.

38 McDonald EL, Bailie R, Michel T. Development and trialling of a tool to support a systems approach to improve social determinants of health in rural and remote Australian communities: the healthy community assessment tool. Int J Equity Health 2013;12:15-10.

39 Schierhout G, Hains J, Si D, et al. Evaluating the effectiveness of a multifaceted, multilevel continuous quality improvement program in primary health care: developing a realist theory of change. Implementation Sci 2013;8:1-15.

40 Brennan SE, Bosch M, Buchan $\mathrm{H}$, et al. Measuring organizational and individual factors thought to influence the success of quality improvement in primary care: a systematic review of instruments. Implement Sci 2012;7:121.

41 Abou Elnour A, Hernan AL, Ford D, et al. Surveyors' perceptions of the impact of accreditation on patient safety in general practice. Med J Aust 2014;201:S56-9.

42 Schmidt B. Personal communication: current status of ACCHS uptake of accreditation standards. Cairns, 2018.

43 Pearson N. Radical hope: education and equality in Australia. Collingwood, Victoria 3066: black Inc, 2011: 202

44 Hunter EM. Indigenous health: radical hope or groundhog day? Med J Aust 2014;200:621-2.

45 Australian Government. Commonwealth of Australia, department of the prime minister and cabinet, closing the gap report 2020. Canberra: Commonwealth of Australia, 2020.

46 Barten F, Mitlin D, Mulholland C, et al. Integrated approaches to address the social determinants of health for reducing health inequity. J Urban Health 2007;84:164-73. 